\title{
Interactive comment on "Active faulting, 3-D basin architecture and Plio-Quaternary structural evolution of extensional basins: a 4-D perspective on the central Apennine chain evolution, Italy" by Stefano Gori et al.
}

\section{Anonymous Referee \#1}

Received and published: 19 August 2016

Comments to the manuscript entitled "Active faulting, 3-D basin architecture and PlioQuaternary structural evolution of extensional basins: a 4-D perspective on the central Apennine chain evolution, Italy" by Gori et al. (doi:10.5194/se-2016-103).

GENERAL COMMENTS The authors present new field geological and geophysical evidence of the role played by a chain-crossing fault in the development of one of the Quaternary extensional intermontane basins of central Apennine. In particular, detailed outcrop and borehole stratigraphic data coupled with ambient seismic noise measurements are collected to reconstruct the 3-D basin architecture and to compare

Printer-friendly version

Discussion paper 
it to the one of adjacent basins bounded by the same chain-crossing fault. The results are then discussed in a wider perspective, to infer that the Apennine extensional morpho-tectonic setting is controlled by the superposition of pre-Quaternary deformation events, whose "legacy" makes a simple "basin and range" model too simplistic for explaining the Quaternary kinematic evolution of central Apennine. The topic is within the scope of SE, the manuscript is well structured, clear and presents new data. The results are sufficient to support substantial conclusions, although some specific comments on the interpretations are listed below. The scientific method and the assumptions are valid and clearly outlined and the results are mostly traceable. The authors give proper credit to related work and clearly indicate their own original contribution. The abstract provides a concise and complete summary of the work and the number and quality of references are appropriate. The quality and content of figures and supplementary material is good, although some improvements are suggested (see "specific comments" below). On the contrary, the title seems overestimating the regional implications of the results, although a moderate re-organization of the Introduction and Discussion could fix this problem (see "specific comments" below). The manuscript should be suitable for publication in Solid Earth after some minor to moderate revision.

SPECIFIC COMMENTS Individual scientific questions/issues are listed below:

-TITLE: Is the case study representative enough of central Apennine to justify the title, in terms of regional implications of the results obtained? The new 3-D basin architecture data from the Subequana Valley are compared to the ones already available for two adjacent basins, which are however bounded by the same chain-crossing fault (Avezzano-Bussi Fault). Just in the Discussion the authors refer to another chaincrossing structure (bounding the Fossa-S.Demetrio depression), which is inferred to play a role similar to the ABF. In order to outline better the scientific gap to be filled and to strengthen the regional significance of the proposed evolutionary model, a deeper overview of the chain-crossing inherited faults and a state of the art on their possible role played in the Plio-Quaternary evolution of central Apennine should be included in

Printer-friendly version

Discussion paper
Interactive

comment 
the Introduction. Furthermore, the already known chain-crossing faults (i.e. the PrataFontecchio Fault) should be added to Fig. 1 (by specifying their state of activity). If not enough examples of chain-crossing faults can be documented for central Apennine, the title should be rewritten, in order to make it more consistent with the content of the paper.

Interactive

- INTRODUCTION: A re-organiation of at least part of this section is suggested. As anticipated above, in order to justify the regional significance of their results the authors should describe in the Introduction the already documented chain-crossing faults and their possible role in the formation of central Apennine intermontane basins. For example, in the Geological Background section the authors refer to previous interpretation of the ABF fault as a tear fault during the compressional phase responsible for the Apennine chain growth. Is there any other example of such tear faults in the Apennines? In there any documented evidence of their inherited role in Quaternary evolution? If so, they should be described in the Introduction, to justify the regional significance of the multi-phase evolution of the case study through superposition of differently oriented faults.

- GEOLOGICAL FIELD DATA: From the sketch in Fig. 2a the Middle Pleistocene erosional phase (between the two sedimentary infilling phases of the Subequana Valley) seems to have occurred through a first phase of fill-cut terrace (Bull, 1990, Geomorphology, 3, 351-367) formation (by lateral erosion), followed by a phase of river downcutting, before the deposition of the second cycle, isn't it? Do the authors have any explanation for this? Can this sequence of events be recognized regionally or is it a local complex-response to base-level changes related to the activity of faults?

- GEOPHYSICAL SURVEYING IN THE SUBEQUANA VALLEY: When deriving the thickness of the sedimentary cover over rigid bedrock, given the impedance contrast, is it possible calculating the error associated to each depth estimate? This information is quite important to strengthen the interpretation of the 3-D architecture of the basins showed in Fig. 8.

Printer-friendly version

Discussion paper 
- DISCUSSION and CONCLUSIONS: The authors interpret the asymmetric deep geometry of the Subequana Valley and the similar structural evolution and setting of the nearby Fucino and Sulmona basins as an effect of a "double polarity nucleation, with two subsequent phases: an early phase, probably Late Pliocene in age, led by the activity the regional chain-crossing, ENE-WSW trending Avezzano-Bussi fault (ABF), inherited by the compressive tectonic phase. Afterwards, since the Early Pleistocene, the presently active NW-SE basin bounding extensional faults took on the opening of the depressions, with the ABF just playing the role of release fault to accommodate slip on the major faults since then". Nonetheless, the authors also outline that "our observations indicate that geomorphic/structural features that can be related to the $A B F$ (such as rectilinear slopes and bedrock fault planes aligned along the structure) and evidence of Quaternary deposits displaced by fault planes aligned along the $A B F$ are confined within the Fucino, Subequana Valley and Sulmona basins, which are bounded by active normal faults. In the areas in between the depressions, instead, no geomorphic imprints of the ABF on the landscape is seen, and it is just "geologically" detectable for the lateral juxtaposition of different bedrock units". The proposal of an evolutionary model (Fig.9) is highly appreciated. Nonetheless, if the ABF fault was first (re-)activated alone in the Late Pliocene phase, how could authors explain that there is no geomorphological evidence of its activity in the areas between adjacent basins? It seems more reliable a model encompassing a double polarity and the only reactivation, as release faults, of the ABF segments confined within the Fucino, Subequana Valley and Sulmona basins, likely acting simultaneously to the NW-SE major ones. In fact, the authors also state (PAGE 11, LINE 8-9): "The major active faults on the eastern border of both of the depressions are active since the Late Pliocene-Early Pleistocene".

TECHNICAL CORRECTIONS

\section{PAGE 1}

LINE 1: The deletion of "4-D" is suggested, which is maybe not necessary and quite "heavy" in combination with "3-D" in the first part of the title LINE 7: change "aspect"

Printer-friendly version

Discussion paper
Interactive

comment 
into "appearance" LINE 23: maybe "inherited faults" could be added to keywords LINE 28: could a short sentence be added to explain the reason for simultaneous faulting SED and regional uplift?

\section{PAGE 2}

LINE 6: maybe better "relict landscape" than "paleo-landscape"? LINE 7: change "montane" into "mountain"

\section{PAGE 3}

LINE 3: change "project of" into "project by" LINE 13: change "repaired" into "protected"

\section{PAGE 4}

LINE 19: delete "been" LINE 20: is the pre-Quaternary fault identifed by Nocentini represented in Fig.1? How is it oriented? You should indicate it explicitly

\section{PAGE 5}

LINE 18: add "to" between "leading" and "the"

\section{PAGE 6}

LINE 9: change "project of" into "project by" LINE 16: "clastic deposition" sounds a bit generic. Please, specify the genesis of the deposits. LINE 26: change "ten" into "tens"

\section{PAGE 7}

LINE 4: change "substratum" into "bedrock" and "suspended over" into "hanging above" LINE 4: change "hanged" into "hanging" LINE 9: change "in the hanging wall of" into "in both the hanging wall and footwall of" LINE 14-15: delete "From a structural viewpoint" LINE 31: change "suspended over" into "hanging above"

\section{PAGE 8}

LINE 7: change "extensional movement" into "normal dip-slip displacement" LINE 18: 
Sant'Anna Valley and Popoli are not indicated in any figure LINE 21: delete one of the points in "Giaccio et al.." LINE 30: change "surveying" into "survey" LINE 32: change "interface bedrock-sedimentary cover" into "bedrock-sedimentary fill interface"

PAGE 9

LINE 21: change "basi" into "basin" LINE 28: change "strain shear" into "shear strain"?

\section{PAGE 10}

LINE 3: change "superficial" into "surface" or "shallow"? LINE 8-9: delete "considered as" LINE 11: change "“contained" within" into "included in" LINE 12: what do you mean with "relative thickness"? Do you mean H? Isn't it the sediment thickness? LINE 16: change "estimate" into "the geometry" LINE 19: maybe instead of "the depth of the interface is obtained by subtracting the sediment thickness from the topographic height of each measurement point" you mean "the absolute elevation of the interface is obtained by subtracting the sediment thickness from the topographic height of each measurement point". . .Nonetheless, in figs. 7 and 8 you show the sediment thickness and not the absolute elevation of the interface, which would definitely outline the "buried topography" of the bedrock-sediment interface. Please, coss-check the content of text and figures. LINE 23: "rises" instead of "rises to"; "a high" instead of "an high" and "scarp" instead of "cliff" LINE 25-26: "thickness of deposits" instead of "deposits thickness" LINE 26: change ", that is, they" into ". These boreholes"

\section{PAGE 11}

LINE 5-6: change "On the other hand" into "Consistently," LINE 31-32: I suggest reviewing the scheme in Fig. 9, by taking into account the possibility that the ABF acted as release fault since the Late Pliocene, along with the major active faults on the eastern border of both of the depressions (Fucino and Subequana), active since the Late Pliocene-Early Pleistocene (as stated on page 11, line 8-9) 
I suggest re-writing the Discussion after having moved in the Introduction part of the text (the one on other chain-crossing faults already documented for Central Apennine; see "general comments")

PAGE 12-13

I suggest re-writing Conclusions according to the eventual review of the evolutionary model

\section{PAGE 19}

LINE 20: change "Apennines" with "Apennine"?

\section{PAGE 21}

LINE 27: Add "deposits" after "lacustrine" and, at the end of caption, add "(see Fig. 2 for the section trace)"

\section{PAGE 23}

LINE 15: delete "derived"

\section{FIGURES:}

FIG.1: i) are all the faults in Fig. 1 active? Maybe better specifying in the caption; ii) I suggest show in this figure also the other chain-crossing fault (if any) already documented for central Apennine (at least the one cited in the Discussion (Prata-Fontecchio fault).

FIG.2: i) what's the difference between white and gray in the Quaternary continental sequences? ii) indicate that section B'-B is in Fig. 3; iii) change "stream/river incision" into "stream/river"; iv) the infilling units in the inset are different from those in the map. . please, homogenise them.

FIG.3: I suggest adding a line drawing also to the upper right inset (lacustrine outcrop on footwall). 
FIG.4: Why in the first and second step the depocentre is located in the SW margin of the depression? This seems not in agreement with the geophysical data. Furthermore, isn't the SW margin bounded by an antithetic fault (even if uncertain)? (see Fig. 2)

FIG.5: In my opinion neither the drag of breccias (5a) nor the faulting of slope deposits (5b) are so evident in this figure. Mybe better adding two zoomed insets?

FIG.6: Symbols for the strike-slip component of displacement are missing

FIG.7: i) please, check the minimum text size (it seems too small for some places); ii) to make the results more readable, I suggest adding to fig. $7 \mathrm{~b}$ the contour lines for sediment thickness or (even better) showing the interpolated topography (color scale and contours) of the buried sediment/bedrock interface (from point data you obtained by subtracting the sediment thickness to the elevation of sampling points)

FIG.8: As for fig. 7b, to make the results more readable I suggest adding the contour lines for sediment thickness or (even better) showing the interpolated topography (color scale and contours) of the buried sediment/bedrock interface (from point data you obtained by subtracting the sediment thickness to the elevation of sampling points)

FIG.9: I suggest reviewing the sketch in the light of the possibility that the ABF acted in the Plio-Quaternary just as release fault (see comments above)

SUPPLEMENTARY MATERIAL FIG. S1: i) I suggest adding a color scale and contour labeling for the depth; ii) If possible, I suggest calculating the error of the depth estimates and using symbol properties to highlight the goodness of each point depth estimate

TAB S1: I suggest adding a column with error associated to each depth estimate FIG. S2: Maybe better explaining the meaning of the three curves in the NHVSR plots?

Interactive comment on Solid Earth Discuss., doi:10.5194/se-2016-103, 2016. 